\title{
Comparative Microarray Analysis of Proliferating and Differentiating Murine ENS Progenitor Cells
}

\author{
Peter Helmut Neckel, Roland Mohr, Ying Zhang, Bernhard Hirt, and Lothar Just \\ Institute of Clinical Anatomy and Cell Analysis, University of Tübingen, Österbergstrasse 3, 72074 Tübingen, Germany \\ Correspondence should be addressed to Lothar Just; ljust@anatom.uni-tuebingen.de
}

Received 15 May 2015; Accepted 12 July 2015

Academic Editor: Kodandaramireddy Nalapareddy

Copyright ( 2016 Peter Helmut Neckel et al. This is an open access article distributed under the Creative Commons Attribution License, which permits unrestricted use, distribution, and reproduction in any medium, provided the original work is properly cited.

\begin{abstract}
Postnatal neural progenitor cells of the enteric nervous system are a potential source for future cell replacement therapies of developmental dysplasia like Hirschsprung's disease. However, little is known about the molecular mechanisms driving the homeostasis and differentiation of this cell pool. In this work, we conducted Affymetrix GeneChip experiments to identify differences in gene regulation between proliferation and early differentiation of enteric neural progenitors from neonatal mice. We detected a total of 1333 regulated genes that were linked to different groups of cellular mechanisms involved in cell cycle, apoptosis, neural proliferation, and differentiation. As expected, we found an augmented inhibition in the gene expression of cell cycle progression as well as an enhanced mRNA expression of neuronal and glial differentiation markers. We further found a marked inactivation of the canonical Wnt pathway after the induction of cellular differentiation. Taken together, these data demonstrate the various molecular mechanisms taking place during the proliferation and early differentiation of enteric neural progenitor cells.
\end{abstract}

\section{Introduction}

The enteric nervous system (ENS) is a largely autonomous and highly complex neuronal network found in the gastrointestinal tract. Its two major plexuses are integrated into the layered anatomy of the gut wall and, together with central modulating influences, exert control over gastrointestinal motility, secretion, ion-homeostasis, and immunological mechanisms [1]. In order to achieve this variety of functions, the ENS is composed of a multitude of different neuronal and glial cell types and closely interacts with smooth muscle cells and myogenic pacemaker cells called interstitial cells of Cajal. Furthermore, a population of neural stem or progenitor cells in the ENS has been identified in rodents [2,3] and humans that retain their proliferative capacity throughout adult life even into old age $[4,5]$. It is therefore not surprising that the correct functioning of the ENS as well as the regulation on enteric neural progenitor cells is subjected to the influence of a myriad of transmitters, neurotrophic and growth factors, signalling molecules, and extracellular matrix components, which are not exclusively expressed by neural cell types [6].
Likewise, the control of the development of the ENS is equally complex and mutations in its genetic program can lead to fatal dysplasia like Hirschsprung's disease (HCSR) $[7,8]$.

HSCR is hallmarked by an aganglionic distal bowel leading to life-threatening disturbances in intestinal motility. Today's therapeutic gold standard, the surgical resection of the affected gut segments, is nevertheless associated with problematic long-term outcomes with regard to continence [9]. In order to improve the therapeutic success, the use of autologous enteric neural stem cells was proposed [10]. This concept relies on the in vitro expansion of enteric neural stem cells derived from small biopsy materials. However, we are just beginning to understand the molecular mechanisms that underlie neural stem cell biology and how this knowledge can be used for optimizing in vitro culture conditions $[11,12]$.

Genome-wide gene-expression analyses are a useful tool to examine the genetic programs and cellular interactions and have been widely used to identify potential markers or signalling mechanisms especially in CNS neurospheres or cancer tissues. Further, gene-expression assays have also helped to unravel genetic prepositions associated with HSCR 
$[13,14]$, though little effort has so far been put into characterizing the genetic profile of enteric neural stem cells in vitro [15].

Here, we used an Affymetrix microarray analysis to evaluate the genetic expression profile of proliferating murine enteric neural stem cells and its changes during the early differentiation in vitro.

\section{Materials and Methods}

2.1. Cell Culturing. Cell culturing was conducted as described previously [15]. The handling of animals was in accordance to the institutional guidelines of the University of Tuebingen, which conform to the international guidelines.

Neonatal (P0) C57BL/6 mice without regard to sex were decapitated and the whole gut was removed. After removal of adherent mesentery the longitudinal and circular muscle layers containing myenteric plexus could be stripped as a whole from the small intestine. Tissue was chopped and incubated in collagenase type XI (750 U/mL; Sigma-Aldrich, Taufkirchen, Germany) and dispase II $(250 \mu \mathrm{g} / \mathrm{mL}$; Roche Diagnostics, Mannheim, Germany) dissolved in Hanks' balanced salt solution with $\mathrm{Ca}^{2+} / \mathrm{Mg}^{2+}$ (HBSS; PAA, Pasching, Austria) for $30 \mathrm{~min}$ at $37^{\circ} \mathrm{C}$. During enzymatic dissociation the tissue was carefully triturated every $10 \mathrm{~min}$ with a fire polished $1 \mathrm{~mL}$ pipette tip. Prior to the first trituration step, cell suspension was treated with $0.05 \%$ (w/v) DNAse I (SigmaAldrich). After $30 \mathrm{~min}$, tissue dissociation was stopped by adding fetal calf serum (FCS; PAA) to a final concentration of $10 \%(\mathrm{v} / \mathrm{v})$ to the medium. Undigested larger tissue pieces were removed with a $40 \mu \mathrm{m}$ cell strainer (BD Biosciences, Franklin Lakes, NJ, USA). Residual enzymes were removed during two washing steps in HBSS at $200 \mathrm{~g}$. After dissociation, cells were resuspended in proliferation culture medium (Dulbecco's modified Eagle's medium with Ham's F12 medium (DMEM/F12; $1: 1 ;$ PAA)) containing N2 supplement (1:100; Invitrogen, Darmstadt, Germany), penicillin $(100 \mathrm{U} / \mathrm{mL}$; PAA), streptomycin (100 $\mu \mathrm{g} / \mathrm{mL}$; PAA), L-glutamine ( $2 \mathrm{mM}$; PAA), epidermal growth factor (EGF; $20 \mathrm{ng} / \mathrm{mL}$; SigmaAldrich), and fibroblast growth factor (FGF; $20 \mathrm{ng} / \mathrm{mL}$; Sigma-Aldrich). Cells were seeded into 6 -well plates (BD Biosciences) in a concentration of $2.5 \times 10^{4} \mathrm{cells} / \mathrm{cm}^{2}$. Only once before seeding, the medium was supplemented with B27 (1:50; Invitrogen). EGF and FGF were added daily and culture medium was exchanged every 3 days. All cultivation steps were conducted in a humidified incubator at $37^{\circ} \mathrm{C}$ and $5 \% \mathrm{CO}_{2}$. An overview of the following cell culture protocol is shown in Figure 1. During proliferation phase of the culture, cells formed spheroid-like bodies termed enterospheres. After 5 days of proliferation, free-floating enterospheres were picked and transferred to petri dishes $(\varnothing$ $60 \mathrm{~mm}$; Greiner Bio One, Frickenhausen, Germany) in $5 \mathrm{~mL}$ fresh proliferation medium and proliferation was continued for further 4 days.

Single free-floating enterospheres (50 enterospheres/ dish) were picked again, washed 3 times in Tris buffer, and transferred into new petri dishes containing either proliferation medium or differentiation medium. Differentiation medium consists of DMEM/F12 containing N2 supplement
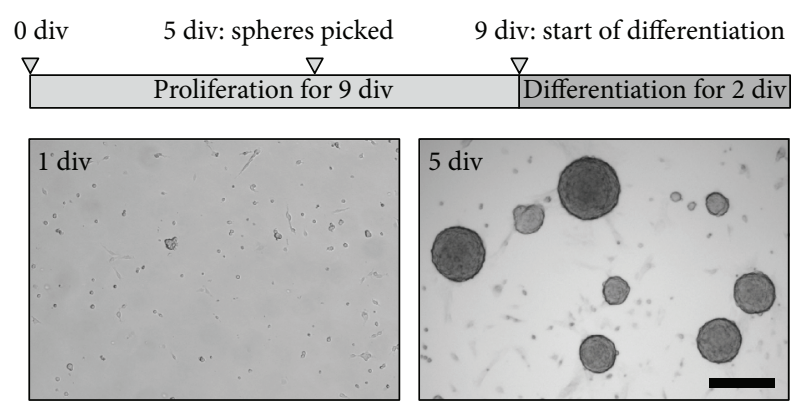

Figure 1: Time schedule of enterosphere culture. The timeline illustrates the schedule of in vitro culture. Cells were isolated at 0 div (days in vitro) and proliferated for 5 days. Spheres were then picked and again proliferated for 4 days. At 9 div, enterospheres were picked, washed, transferred to differentiation medium, and incubated for 2 days before gene expression analyses were carried out. The micrographs show proliferating enterospheres after 1 and 5 div. Scale bar: $200 \mu \mathrm{m}$.

(1:100), penicillin $(100 \mathrm{U} / \mathrm{mL})$, streptomycin $(100 \mu \mathrm{g} / \mathrm{mL}), \mathrm{L}-$ glutamine $(2 \mathrm{mM})$, and ascorbic acid-2-phosphate $(200 \mu \mathrm{M}$; Sigma-Aldrich).

Enterospheres were proliferated or differentiated for 2 more days, thereby forming the two experimental groups "proliferation" and "differentiation." The difference in expression between those two groups (differentiation versus proliferation) was successively compared by microarray analysis as described below.

2.2. Affymetrix Microarray Analysis. Affymetrix microarray analysis was conducted similar to previously published data in three independent experiments, each with cell cultures prepared from 2 pups from the same litter [15]. In each experiment, free-floating enterospheres were picked as described above in order to diminish the fraction of adhesive fibroblasts and smooth muscle cells.

Total RNA of enterospheres of both groups was extracted using the RNeasy Micro Kit (Qiagen). RNA quality was evaluated on Agilent 2100 Bioanalyzer with RNA integrity numbers (RIN) of the samples in this study being in the range from 8 to 10 . RIN numbers higher than 8 are considered optimal for downstream application [16].

Double-stranded cDNA was synthesized from $100 \mathrm{ng}$ of total RNA, subsequently linearly amplified, and biotinylated using the GeneChip WT cDNA Synthesis and Amplification Kit (Affymetrix, Santa Clara, CA, USA) according to the manufacturer's instructions. $15 \mu \mathrm{g}$ of labeled and fragmented cDNA was hybridized to GeneChip Mouse Gene 1.0 ST arrays (Affymetrix). After hybridization, the arrays were stained and washed in a Fluidics Station 450 (Affymetrix) with the recommended washing procedure. Biotinylated cDNA bound to target molecules was detected with streptavidincoupled phycoerythrin, biotinylated anti-streptavidin IgG antibodies and again streptavidin-coupled phycoerythrin according to the protocol. Arrays were scanned using the GCS3000 GeneChip Scanner (Affymetrix) and AGCC 3.0 software. Scanned images were subjected to visual inspection 
to check for hybridization artifacts and proper grid alignment and analyzed with Expression Console 1.0 (Affymetrix) to generate report files for quality control.

Normalization of raw data was performed by the Partek Software 6.6, applying an RMA (Robust Multichip Average) algorithm. Significance was calculated using a $t$-test without multiple testing correction (Partek), selecting all transcripts with a minimum change in expression level of 1.5 -fold together with a $p$ value less than 0.05 .

\section{Results}

In this study, we investigated the changes of the genetic expression profile that occur during the transition from proliferating to differentiating enteric neural progenitor cells in vitro. Therefore, we generated enterospheres by 9 day in vitro cultures, which then could be picked and either proliferated or differentiated for two more days (Figure 1). mRNA was subsequently extracted and gene expression of these two groups was analysed by Affymetrix microarray analysis.

Analysis of mRNA expression was performed on a GeneChip Mouse Gene 1.0 ST array that determines the expression profile of 28.853 genes. Each gene was interrogated by a median of 27 probes that are spread along the full gene.

In total, the gene chip detected 1454 transcripts to be at least 1.5 -fold differentially expressed between proliferating and differentiating enterospheres. 1333 of these transcripts code for already identified proteins. 541 genes were found to be upregulated and 792 genes were found to be downregulated in comparison to proliferating enterospheres (see Supplementary Table 1 of the Supplementary Material available online at http://dx.doi.org/10.1155/2016/9695827).

We used the ingenuity pathway analysis software (IPA) and data mining with the science literature search engine http://www.ncbi.nlm.nih.gov/pubmed/ to divide the genes into different groups according to their function during cellular development. The largest functional group contained 171 genes related to cell cycle and apoptosis (Table 1, Supplementary Table 2). Here, we identified especially different cyclin proteins and cell division cycle proteins that were mainly downregulated. Further, we found several genes that are linked to neural development as well as genes regulating neural stem cell proliferation and differentiation. Furthermore, we also detected neuronal and glial differentiation markers and numerous genes involved in synapse formation (Table 2). It is noteworthy that we also identified a group of genes that are known to be involved in the differentiation of smooth muscle cells (Table 3 ) as well as in extracellular matrix components (Table 4). Additionally, we found regulated genes related to canonical Wnt signalling indicating a deactivation of this pathway during ENS progenitor cell differentiation (Figure 2, Table 5).

\section{Discussion}

The proliferation and differentiation of enteric neural progenitor cells during embryonic and postnatal development are controlled by a complex interplay of various intrinsic
TABLE 1: Selected genes related to cell cycle.

\begin{tabular}{|c|c|c|c|}
\hline Gene & Encoded protein & $\begin{array}{l}\text { Fold } \\
\text { change }\end{array}$ & Cell cycle \\
\hline AURKA & Aurora kinase A & -2.712 & STOP \\
\hline AURKB & Aurora kinase B & -4.146 & STOP \\
\hline CCNA2 & Cyclin A2 & -4.652 & STOP \\
\hline CCNB1 & Cyclin B1 & $\begin{array}{l}-5.752 \\
-5.820 \\
-5.857\end{array}$ & STOP \\
\hline CCNB2 & Cyclin B2 & -3.392 & STOP \\
\hline CCND1 & Cyclin D1 & -2.476 & STOP \\
\hline CCND3 & Cyclin D3 & -1.539 & STOP \\
\hline CCNE1 & Cyclin E1 & -1.777 & STOP \\
\hline CCNE2 & Cyclin E2 & -2.847 & STOP \\
\hline CCNF & Cyclin F & -3.211 & STOP \\
\hline CDC6 & Cell division cycle 6 & -1.936 & STOP \\
\hline $\mathrm{CDC} 20$ & Cell division cycle 20 & -3.113 & STOP \\
\hline CDC25B & Cell division cycle 25B & -1.636 & STOP \\
\hline CDC25C & Cell division cycle $25 \mathrm{C}$ & -2.414 & STOP \\
\hline CDC45 & Cell division cycle 45 & -1.769 & STOP \\
\hline CDCA2 & Cell division cycle associated 2 & -3.461 & STOP \\
\hline CDCA3 & Cell division cycle associated 3 & -3.003 & STOP \\
\hline CDCA5 & Cell division cycle associated 5 & -3.053 & STOP \\
\hline CDCA7L & $\begin{array}{l}\text { Cell division cycle associated } \\
\text { 7-like }\end{array}$ & -4.123 & STOP \\
\hline CDCA8 & Cell division cycle associated 8 & -3.467 & STOP \\
\hline CDK1 & Cyclin-dependent kinase 1 & -3.227 & STOP \\
\hline CDK15 & Cyclin-dependent kinase 15 & 1.618 & GO \\
\hline CDK19 & Cyclin-dependent kinase 19 & 1.619 & GO \\
\hline CDK5R1 & $\begin{array}{l}\text { Cyclin-dependent kinase } 5 \text {, } \\
\text { regulatory subunit } 1 \text { (p35) }\end{array}$ & 1.597 & - \\
\hline CENPA & Centromere protein A & -1.895 & STOP \\
\hline CENPE & Centromere protein E, $312 \mathrm{kDa}$ & -4.140 & STOP \\
\hline CENPF & $\begin{array}{l}\text { Centromere protein } \mathrm{F} \\
350 / 400 \mathrm{kDa}\end{array}$ & -3.927 & STOP \\
\hline CENPI & Centromere protein I & -2.899 & STOP \\
\hline CENPK & Centromere protein $\mathrm{K}$ & -2.813 & STOP \\
\hline CENPL & Centromere protein L & -1.864 & STOP \\
\hline CENPM & Centromere protein $\mathrm{M}$ & -3.407 & STOP \\
\hline CENPN & Centromere protein $\mathrm{N}$ & -2.465 & STOP \\
\hline CENPU & Centromere protein $\mathrm{U}$ & -1.624 & STOP \\
\hline SKA1 & $\begin{array}{l}\text { Spindle and kinetochore } \\
\text { associated complex subunit } 1\end{array}$ & -1.532 & STOP \\
\hline SKA2 & $\begin{array}{l}\text { Spindle and kinetochore } \\
\text { associated complex subunit } 2\end{array}$ & -1.582 & STOP \\
\hline SKA3 & $\begin{array}{l}\text { Spindle and kinetochore } \\
\text { associated complex subunit } 3\end{array}$ & -3.490 & STOP \\
\hline SKP2 & $\begin{array}{l}\text { S-phase kinase-associated } \\
\text { protein 2, E3 ubiquitin protein } \\
\text { ligase }\end{array}$ & -1.845 & STOP \\
\hline SPC25 & $\begin{array}{l}\text { SPC25, NDC80 kinetochore } \\
\text { complex component }\end{array}$ & -4.148 & STOP \\
\hline
\end{tabular}


TABle 2: Neural differentiation/development.

\begin{tabular}{|c|c|c|}
\hline Gene & Encoded protein & Fold change \\
\hline \multicolumn{3}{|c|}{ Neural stem cells } \\
\hline ABCG2 & ATP-binding cassette, subfamily G (WHITE), member 2 (junior blood group) & -1.526 \\
\hline ASPM & asp (abnormal spindle) homolog, microcephaly associated (Drosophila) & -4.911 \\
\hline CDT1 & Chromatin licensing and DNA replication factor 1 & -1.528 \\
\hline EGFL7 & EGF-like-domain, multiple 7 & 3.132 \\
\hline EPHA2 & EPH receptor A2 & -1.529 \\
\hline ETV4 & ets variant 4 & -1.934 \\
\hline ETV5 & ets variant 5 & -2.844 \\
\hline & & -2.651 \\
\hline FABP7 & Fatty acid binding protein 7 , brain & -2.095 \\
\hline \multicolumn{3}{|c|}{ Neural differentiation } \\
\hline ATOH8 & Atonal homolog 8 (Drosophila) & 1.932 \\
\hline AXL & AXL receptor tyrosine kinase & 2.015 \\
\hline CRIM1 & Cysteine-rich transmembrane BMP regulator 1 (chordin-like) & 1.999 \\
\hline CRLF1 & Cytokine receptor-like factor 1 & 2.382 \\
\hline DAB1 & Dab, reelin signal transducer, homolog 1 (Drosophila) & -2.297 \\
\hline ELK3 & ELK3, ETS-domain protein (SRF accessory protein 2) & -1.613 \\
\hline $\mathrm{ESCO} 2$ & Establishment of sister chromatid cohesion $\mathrm{N}$-acetyltransferase 2 & -4.767 \\
\hline GAP43 & Growth associated protein 43 & 1.613 \\
\hline GLDN & Gliomedin & 5.809 \\
\hline HMOX1 & Heme oxygenase (decycling) 1 & 1.884 \\
\hline KLF9 & Kruppel-like factor 9 & 1.592 \\
\hline Lmo3 & LIM domain only 3 & 1.542 \\
\hline MAP6 & Microtubule-associated protein 6 & 1.874 \\
\hline MYRF & Myelin regulatory factor & 2.527 \\
\hline NEUROD4 & Neuronal differentiation 4 & 2.036 \\
\hline OLIG1 & Oligodendrocyte transcription factor 1 & 2.660 \\
\hline Pvr & Poliovirus receptor & 1.768 \\
\hline RGS4 & Regulator of G-protein signaling 4 & 1.955 \\
\hline S1PR1 & Sphingosine-1-phosphate receptor 1 & 5.073 \\
\hline SOCS2 & Suppressor of cytokine signaling 2 & 2.052 \\
\hline & & 2.335 \\
\hline WIPF1 & WAS/WASL interacting protein family, member 1 & 1.587 \\
\hline \multicolumn{3}{|c|}{ Neural differentiation markers } \\
\hline CALB2 & Calbindin 2 & 1.616 \\
\hline $\mathrm{CNP}$ & $2^{\prime}, 3^{\prime}$-Cyclic nucleotide $3^{\prime}$-phosphodiesterase & 1.732 \\
\hline GFAP & Glial fibrillary acidic protein & 2.239 \\
\hline MBP & Myelin basic protein & 1.768 \\
\hline Mturn & Maturin, neural progenitor differentiation regulator homolog (Xenopus) & 1.853 \\
\hline OMG & Oligodendrocyte myelin glycoprotein & -1.822 \\
\hline OPALIN & Oligodendrocytic myelin paranodal and inner loop protein & 39.246 \\
\hline PLP1 & Proteolipid protein 1 & 1.630 \\
\hline S100B & S100 calcium binding protein B & -1.675 \\
\hline TUBB2A & Tubulin, beta $2 \mathrm{~A}$ class IIa & 1.608 \\
\hline TUBB2B & Tubulin, beta 2B class IIb & 1.535 \\
\hline TUBB3 & Tubulin, beta 3 class III & 1.976 \\
\hline
\end{tabular}


TABle 2: Continued.

\begin{tabular}{|c|c|c|}
\hline Gene & Encoded protein & Fold change \\
\hline \multicolumn{3}{|c|}{ Synapse and neurotransmitters } \\
\hline ABAT & 4-Aminobutyrate aminotransferase & -1.512 \\
\hline ADRA1D & Adrenoceptor alpha 1D & 1.803 \\
\hline ADRA2A & Adrenoceptor alpha $2 \mathrm{~A}$ & 2.900 \\
\hline ADRA2B & Adrenoceptor alpha 2B & -2.093 \\
\hline CHRM2 & Cholinergic receptor, muscarinic 2 & 1.635 \\
\hline CHRM3 & Cholinergic receptor, muscarinic 3 & -1.715 \\
\hline CHRNA7 & Cholinergic receptor, nicotinic, alpha 7 (neuronal) & 1.772 \\
\hline COMT & Catechol-O-methyltransferase & 1.515 \\
\hline DDC & DOPA decarboxylase (aromatic L-amino acid decarboxylase) & 1.711 \\
\hline DNM3 & Dynamin 3 & 2.643 \\
\hline EPHA5 & EPH receptor A5 & 2.076 \\
\hline GRIA3 & Glutamate receptor, ionotropic, AMPA 3 & -1.528 \\
\hline GRIA4 & Glutamate receptor, ionotropic, AMPA 4 & -1.997 \\
\hline GRIK2 & Glutamate receptor, ionotropic, kainate 2 & -1.565 \\
\hline GRM5 & Glutamate receptor, metabotropic 5 & -1.600 \\
\hline HTR1B & 5-Hydroxytryptamine (serotonin) receptor 1B, G-protein-coupled & -2.377 \\
\hline HTR2B & 5-Hydroxytryptamine (serotonin) receptor 2B, G-protein-coupled & 2.205 \\
\hline LRRTM2 & Leucine-rich repeat transmembrane neuronal 2 & 3.665 \\
\hline LRRTM3 & Leucine-rich repeat transmembrane neuronal 3 & 2.210 \\
\hline NTM & Neurotrimin & 1.820 \\
\hline PENK & Proenkephalin & 3.478 \\
\hline PRR7 & Proline rich 7 (synaptic) & 1.788 \\
\hline \multirow[t]{2}{*}{ SLC10A4 } & Solute carrier family 10 , member 4 & 1.824 \\
\hline & & 1.867 \\
\hline SLITRK2 & SLIT and NTRK-like family, member 2 & -2.414 \\
\hline SLITRK6 & SLIT and NTRK-like family, member 6 & 1.672 \\
\hline STON2 & Stonin 2 & 4.054 \\
\hline STXBP3 & Syntaxin-binding protein 3 & 1.730 \\
\hline Stxbp3b & Syntaxin-binding protein $3 \mathrm{~B}$ & 1.637 \\
\hline SV2C & Synaptic vesicle glycoprotein $2 \mathrm{C}$ & 1.929 \\
\hline SYT6 & Synaptotagmin VI & 2.571 \\
\hline \multicolumn{3}{|c|}{ Neurite outgrowth } \\
\hline ATF3 & Activating transcription factor 3 & 2.579 \\
\hline DOK4 & Docking protein 4 & 4.937 \\
\hline FEZ2 & Fasciculation and elongation protein zeta 2 (zygin II) & 1.547 \\
\hline NAV2 & Neuron navigator 2 & 1.647 \\
\hline NRCAM & Neuronal cell adhesion molecule & 2.496 \\
\hline PLXNB3 & Plexin B3 & 1.739 \\
\hline RGMA & Repulsive guidance molecule family member a & 1.552 \\
\hline RNF165 & Ring finger protein 165 & -1.548 \\
\hline $\mathrm{ROBO} 2$ & Roundabout, axon guidance receptor, homolog 2 (Drosophila) & -2.211 \\
\hline SEMA3B & Sema domain, immunoglobulin domain (Ig), short basic domain, secreted (semaphorin) 3B & 3.692 \\
\hline SEMA3E & Sema domain, immunoglobulin domain (Ig), short basic domain, secreted (semaphorin) 3E & 2.877 \\
\hline SEMA4F & $\begin{array}{l}\text { Sema domain, immunoglobulin domain (Ig), transmembrane domain (TM) and short } \\
\text { cytoplasmic domain, (semaphorin) } 4 \mathrm{~F}\end{array}$ & 4.891 \\
\hline SEMA6A & Sema domain, transmembrane domain (TM), and cytoplasmic domain (semaphorin) 6A & -1.707 \\
\hline SRGAP1 & SLIT-ROBO Rho GTPase activating protein 1 & 1.524 \\
\hline UNC5B & unc-5 homolog B (C. elegans) & -1.927 \\
\hline
\end{tabular}


TABLE 2: Continued.

\begin{tabular}{llr}
\hline Gene & Encoded protein & Fold change \\
\hline & & \\
ARTN & Artemin & \\
FGF2 & Fibroblast growth factor 2 (basic) & 2.423 \\
FGF5 & Fibroblast growth factor 5 & 2.264 \\
GDF10 & Growth differentiation factor 10 & 7.704 \\
GDF11 & Growth differentiation factor 11 & -2.361 \\
GDNF & Glial cell derived neurotrophic factor & 1.604 \\
GFRA3 & GDNF family receptor alpha 3 & 4.325 \\
MET & MET protooncogene, receptor tyrosine kinase & 1.707 \\
NGFR & Nerve growth factor receptor & 6.680 \\
NTRK3 & Neurotrophic tyrosine kinase, receptor, type 3 & 1.728 \\
SNX16 & Sorting nexin 16 & -1.575 \\
SPHK1 & Sphingosine kinase 1 & 1.641 \\
SPRY1 & Sprouty homolog 1, antagonist of FGF signaling (Drosophila) & 1.704 \\
\hline
\end{tabular}

and extrinsic factors. Their exact timing is crucial for proper migration and proliferation of neural crest cells and for their differentiation into the various neural cell types that compose the complex neural structures of the ENS. Although research in recent years extended our understanding of ENS development and its pathologies [13], there are still many genes and processes unknown. Particularly, factors regulating neural progenitor proliferation and differentiation in the developing and postnatal gut as well as cellular and molecular interaction systems remain largely elusive. Here, we used in vitro cultures of enteric neural progenitor cells derived from murine tunica muscularis to scan for molecular programs and signalling pathways acting on cell proliferation and early differentiation.

Our experiment aimed to elucidate gene regulations in enterospheres that occur while ENS progenitor cells leave their proliferative state and begin to differentiate into more defined and specific cell types. The results of the Affymetrix gene expression analysis showed the up- and downregulation of overall 1333 known genes that code for already identified proteins. 171 of these genes could be linked to cell proliferation (Table 1, Supplementary Table 1). Amongst them we detected genes coding for proteins related to the kinetochore complex (like NSL1 [17], NUF2 [18], SKA1-3 [19], and ZWILCH [20]), cyclin proteins [21], cyclin-dependent kinases (CDK) [22], and several types of centromere proteins. The regulation of 145 of these genes strongly indicates a slowdown of cell cycle progression as it was intended by the experimental deprivation of growth factor supplementation by the end of the proliferation phase (see Section 3). Interestingly, betacellulin (BTC) was upregulated nearly 6fold although it was reported to promote cellular proliferation in the neural stem cell niche [23]. Nonetheless, the vast majority of genes including all regulated cyclins, cell division cycle proteins, and kinetochore proteins were found to be downregulated.

We also checked the regulated genes for apoptosis markers to see whether the stop in proliferation was related to cell death (Supplementary Table 2). Since only 3 of 12 apoptotic genes were regulated in the direction that indicates apoptosis, it is unlikely that apoptosis played a leading role in the interruption of proliferation. Still, the effect and regulation of apoptosis during enteric sphere cultures are an important cornerstone of understanding enteric neural progenitors in culture and in vivo and require further investigation. Together, on a broad basis, this dataset provides strong evidence that this cell culture design is applicable to decreasing the proliferative rate of enteric neural progenitor cells without inducing cell death or apoptosis in an appreciable quantity.

To further evaluate the proliferative conditions of cell types present in enterospheres, we focused on different cell specific markers of neural progenitors as well as neurons, glial, or smooth muscle cells. We consider this complex cellular composition of the enterospheres an advantage compared to more purified neural crest derived neurospheres as we are able to capture complex interactions and secretion mechanisms between cell types that might also play an important role in vivo. Interestingly, we found 8 genes involved in adult central or embryonic neural stem cells homeostasis (Table 2). The majority of genes like EPHA2 [24] are regulated in a way that suggests that neural stem cells exit the proliferative cell cycle to enter differentiation programs. This idea was supported by the upregulation of numerous genes that drive neuronal and glial differentiation like NEUROD4 [25] or OLIG1 [26]. In this context, we identified several upregulated genes involved in proper myelination. As enteric and central glia cells are known to temporally express myelin-related proteins during development, it is conceivable that this regulation is part of the early glial differentiation program [27]. Moreover, also typical markers of differentiated neurons (class III beta-tubulin, CALB2 [28]) and enteric glia (GFAP [29]) were found to be upregulated. Intriguingly, S100B, a common glia cell marker, was downregulated contrasting the rest of our data. Again, this might be due to the complex differentiation program of enteric glia, in which S100B plays a role at later stages. 


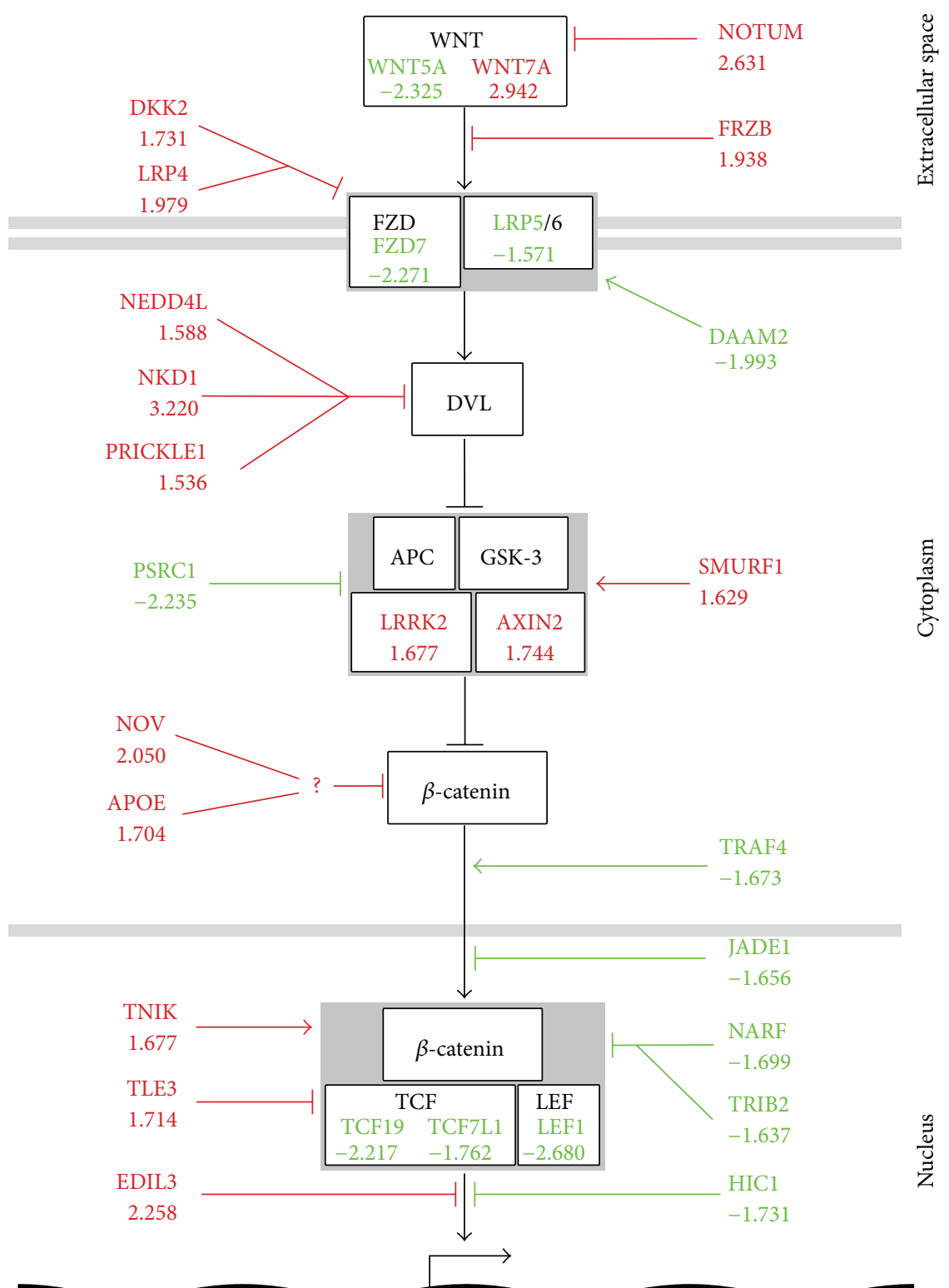

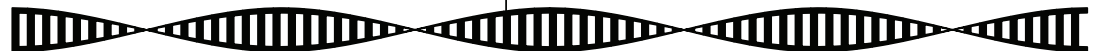

DNA

FIGURE 2: Detected regulatory influences on the canonical Wnt pathway. Scheme of the canonical Wnt pathway. Pointy arrowheads indicate an activating, blunt arrowheads, an inhibitory influence. The fold-change in expression of genes is written under the respective gene acronyms and colours indicate a general upregulation (red) or downregulation (green). For detailed explanation of the signalling cascade and regulated genes, see text.

Furthermore, the establishment of neuronal cell communication was strongly regulated. Here, we found an increased expression of genes related to synaptogenesis (LRRTM2 and 3 [30], neurotrimin [31]) and to SNARE or vesicle protein function (STXBP3, SV2C [32], and SYT6 [33]). We also identified a number of genes involved in transmitter metabolism (COMT, DDC) as well as neurotransmitter receptor like 5-HT, glutamate, and adrenergic receptors. However, the regulation of those genes was highly variable shedding light on the intricacy of synapse formation in the developing enteric nervous system. This complexity is carried on by genes related to axon sprouting and guidance like semaphorins [34] or RGMa [35].

Additionally, we found that regulated genes directly involved in the differentiation of muscle cells and/or enteric pacemaker cells called interstitial cells of Cajal (Table 3). Particularly interesting is the upregulation of a number of genes known to drive smooth muscle differentiation like ARID5B [36], FOSL2 [36] and genes that are expressed in differentiated smooth muscle cells in the intestine like AFAP1 [37], ENPP2 [38], and CNN1 [39] as well as various myosin and actin isoforms. These data confirm the 
TABLE 3: Differentiation of smooth muscle cells/ICCs.

\begin{tabular}{|c|c|c|}
\hline Gene & Encoded protein & Fold change \\
\hline \multicolumn{3}{|c|}{ Smooth muscle cells } \\
\hline ACTA2 & Actin, alpha 2, smooth muscle, aorta & 1.693 \\
\hline ACTG2 & $\begin{array}{l}\text { Actin, gamma 2, smooth muscle, } \\
\text { enteric }\end{array}$ & 2.336 \\
\hline ACTN1 & Actinin, alpha 1 & -1.724 \\
\hline AEBP1 & AE binding protein 1 & 2.702 \\
\hline AFAP1 & Actin filament associated protein 1 & 1.638 \\
\hline ARID5B & $\begin{array}{l}\text { AT-rich interactive domain 5B } \\
\text { (MRF1-like) }\end{array}$ & 1.521 \\
\hline Cald1 & Caldesmon 1 & -1.535 \\
\hline CNN1 & Calponin 1, basic, smooth muscle & 1.652 \\
\hline ENG & Endoglin & -1.552 \\
\hline ENPP1 & $\begin{array}{l}\text { Ectonucleotide } \\
\text { pyrophosphatase/phosphodiesterase } 1\end{array}$ & -1.522 \\
\hline ENPP2 & $\begin{array}{l}\text { Ectonucleotide } \\
\text { pyrophosphatase/phosphodiesterase } 2\end{array}$ & 2.959 \\
\hline ENTPD1 & $\begin{array}{l}\text { Ectonucleoside triphosphate } \\
\text { diphosphohydrolase } 1\end{array}$ & 1.636 \\
\hline FOSL2 & FOS-like antigen 2 & 2.566 \\
\hline GAMT & Guanidinoacetate N-methyltransferase & 1.725 \\
\hline MYO1E & Myosin IE & 1.569 \\
\hline MYO5A & Myosin VA (heavy chain 12 , myoxin) & 1.680 \\
\hline MYO7B & Myosin VIIB & 1.710 \\
\hline MYO18A & Myosin XVIIIA & 1.994 \\
\hline MYPN & Myopalladin & 1.570 \\
\hline NEB & Nebulin & 1.569 \\
\hline Nebl & Nebulette & 2.378 \\
\hline NUP210 & Nucleoporin 210 kDa & -1.838 \\
\hline RBM24 & RNA binding motif protein 24 & 1.548 \\
\hline SMTN & Smoothelin & -1.778 \\
\hline SSPN & Sarcospan & 1.603 \\
\hline TAGLN & Transgelin & 2.706 \\
\hline \multicolumn{3}{|c|}{ ICC } \\
\hline GUCY1A3 & Guanylate cyclase 1, soluble, alpha 3 & -1.876 \\
\hline GUCY1B3 & Guanylate cyclase 1 , soluble, beta 3 & -2.008 \\
\hline KIT & $\begin{array}{l}\text { v-kit Hardy-Zuckerman } 4 \text { feline } \\
\text { sarcoma viral oncogene homolog }\end{array}$ & -1.798 \\
\hline KITLG & KIT ligand & -1.541 \\
\hline
\end{tabular}

fact that cultured spheroids are composed of different cell types present in the intestinal tunica muscularis and further indicate that deprivation of growth factors induces differentiation of smooth muscle cells resembling molecular processes in the developing gut. In fact, we among others were previously able to confirm the presence of smooth muscle cells derived from enterosphere culture by BrdUimmunolabeling costudies [4]. However, it is noteworthy that a few genes related to muscular differentiation (endoglin [40], smoothelin [41], NUP210 [42], caldesmon 1 [43], and ACTN1 [44]) were downregulated contrasting the expression pattern observed in the majority of regulated genes. This hints to complex regulatory mechanisms controlling the myogenic differentiation program in which these genes are not required at all or in a different temporal sequence not mapped by our experimental design. It is further remarkable that five markers expressed in interstitial cells of Cajal (ICC) including KIT [45] were downregulated.

Moreover, the regulation of 43 extracellular matrix proteins like collagens, integrins, proteoglycans, and matrix metallopeptidases points to a reconstruction of extracellular environment that has been discussed to influence neural stem cell behaviour [46] (Table 4). Taken together, these results illustrate the ongoing genetic programs during early differentiation of enterospheres.

Within the dataset, it was of special interest to find particularly many regulated genes related to the canonical Wnt pathway (Table 5). The involvement of canonical Wnt signalling has frequently been shown in the regulation of various stem cell niches, like intestinal epithelium or CNS derived neural stem cells. However, these studies exhibited different and partly contradicting outcomes, which strongly hint to the variable functions of canonical Wnt signals in different tissues during embryonic and postnatal development. In previous work, we found regulation of several Wnt-related genes in the context of thyroid hormone dependent differentiation of enteric neural progenitor cells indicating a potential role of the canonical Wnt pathway activation during the proliferation of this progenitor cell pool [15]. Canonical Wnt signalling has frequently been reviewed in the literature-just recently by Ring et al. [47]. In brief, secreted Wnt proteins bind to frizzled receptors (FZD) complexed with low density lipoprotein receptor-related protein 5/6 (LRP5/6) coreceptors. Thereafter, the scaffolding protein disheveled (DVL) is recruited to FZD and inhibits the $\beta$-catenin destruction complex (AXIN2, APC, and GSK-3 $\beta$ ). Therefore, $\beta$-catenin accumulates in the cytoplasm and translocates to the nucleus where it binds to TCF/LEF transcription factors to initiate Wnt target gene expression. Interestingly, our current data strongly indicate that the canonical Wnt pathway is switched off during the first two days of enteric progenitor differentiation on several levels of the signalling cascade (Figure 2). On the one hand we identified a downregulation of activating parts of the signalling cascade itself like the receptor proteins FZD7 and LRP5 or the transcription factors TCF19, TCF7L1, and LEF1. On the other hand, inactivating elements of the pathway like parts of the $\beta$-catenin destruction complex AXIN2 and LRRK2 [48] were upregulated. We also found numerous modulators of the signalling cascade. It is of interest that the majority of those genes are reported to inhibit the signalling process extracellularly or on receptor level (Notum [49], FRZB [50], DKK2 [51], and LRP4 [52]), in the cytoplasm (NEDD4L [53], NKD1 [54], PRICKLE1 [55], NOV [56], and APOE [57]), or in the nucleus (TLE3 [58], EDIL3 [59]). Furthermore, we identified target genes of the canonical Wnt pathway that were either upregulated (e.g., AXIN2 that exerts a negative feedback on the pathway) or downregulated like the cell cycle progression genes CCND1 and SPRY4 [60]. We also found a lower expression of SPRY2 [61], a Wnt target gene and known inhibitor of GDNF signalling [62], in the differentiation group. Together with a strong upregulation of 
TABLE 4: ECM.

\begin{tabular}{|c|c|c|}
\hline Gene & Encoded protein & Fold change \\
\hline CHSY3 & Chondroitin sulfate synthase 3 & -1.645 \\
\hline COL6A5 & Collagen, type VI, alpha 5 & 1.527 \\
\hline COL12A1 & Collagen, type XII, alpha 1 & -1.973 \\
\hline COL14A1 & Collagen, type XIV, alpha 1 & 6.135 \\
\hline COL16A1 & Collagen, type XVI, alpha 1 & 1.666 \\
\hline COL18A1 & Collagen, type XVIII, alpha 1 & 1.595 \\
\hline COL27A1 & Collagen, type XXVII, alpha 1 & 1.522 \\
\hline COLGALT2 & Collagen beta(1-O)galactosyltransferase 2 & -1.564 \\
\hline CSPG4 & Chondroitin sulfate proteoglycan 4 & -2.952 \\
\hline CSPG5 & Chondroitin sulfate proteoglycan 5 (neuroglycan C) & -1.585 \\
\hline CYR61 & Cysteine-rich, angiogenic inducer, 61 & 1.748 \\
\hline ECM1 & Extracellular matrix protein 1 & 2.580 \\
\hline HSPG2 & Heparan sulfate proteoglycan 2 & 1.923 \\
\hline ITGA1 & Integrin, alpha 1 & -1.665 \\
\hline ITGA4 & Integrin, alpha 4 (antigen CD49D, alpha 4 subunit of VLA-4 receptor) & -2.324 \\
\hline ITGA7 & Integrin, alpha 7 & 4.203 \\
\hline ITGA8 & Integrin, alpha 8 & -2.262 \\
\hline ITGA11 & Integrin, alpha 11 & 1.762 \\
\hline ITGB3 & Integrin, beta 3 (platelet glycoprotein IIIa, antigen CD61) & -5.342 \\
\hline ITGB4 & Integrin, beta 4 & 1.567 \\
\hline KRT80 & Keratin 80 & 2.833 \\
\hline LAMA4 & Laminin, alpha 4 & -1.537 \\
\hline LAMA5 & Laminin, alpha 5 & 1.684 \\
\hline LOX & Lysyl oxidase & 3.250 \\
\hline \multirow[t]{2}{*}{ LOXL4 } & Lysyl oxidase-like 4 & 2.427 \\
\hline & & 2.417 \\
\hline MATN2 & Matrilin 2 & 2.570 \\
\hline MMP2 & Matrix metallopeptidase 2 (gelatinase A, $72 \mathrm{kDa}$ gelatinase, $72 \mathrm{kDa}$ type IV collagenase) & 1.668 \\
\hline MMP9 & Matrix metallopeptidase 9 (gelatinase B, $92 \mathrm{kDa}$ gelatinase, $92 \mathrm{kDa}$ type IV collagenase) & -5.557 \\
\hline MMP15 & Matrix metallopeptidase 15 (membrane-inserted) & -2.017 \\
\hline MMP16 & Matrix metallopeptidase 16 (membrane-inserted) & -1.634 \\
\hline MMP17 & Matrix metallopeptidase 17 (membrane-inserted) & 1.612 \\
\hline MMP19 & Matrix metallopeptidase 19 & 3.236 \\
\hline MMP28 & Matrix metallopeptidase 28 & 1.956 \\
\hline NDST3 & N-deacetylase/N-sulfotransferase (heparan glucosaminyl) 3 & -5.557 \\
\hline P4HA1 & Prolyl 4-hydroxylase, alpha polypeptide I & -1.958 \\
\hline PLOD3 & Procollagen-lysine, 2-oxoglutarate 5-dioxygenase 3 & 2.250 \\
\hline UGDH & UDP-glucose 6-dehydrogenase & 1.529 \\
\hline
\end{tabular}

GDNF itself by 4.325-fold, this might drive enteric progenitor cells into neural differentiation [12].

Taken together, it is conceivable that canonical Wnt signalling plays a role in the maintenance of the enteric progenitor pool during proliferation and is switched off at the beginning of differentiation conditions. Indeed, our previous gene expression analyses [15] as well as recently published cell culture experiments [63] and yet unpublished in vitro analyses strongly support this hypothesis.

\section{Conclusion}

This study focused on the changes in gene expression of enteric neural progenitor cells occurring within the first two days of transition from a proliferative state to differentiation in vitro. Using microarray analysis, we found a marked inhibition of cell cycle progression in general as well as strong evidence for neural stem cells differentiation into enteric neurons and glia cells. These findings were substantiated 
TABLE 5: Wnt.

\begin{tabular}{|c|c|c|}
\hline Gene & Encoded protein & Fold change \\
\hline \multicolumn{3}{|c|}{ Wnt signaling cascade } \\
\hline FZD7 & Frizzled class receptor 7 & -2.271 \\
\hline LEF1 & Lymphoid enhancer-binding factor 1 & -2.680 \\
\hline LRP5 & Low density lipoprotein receptor-related protein 5 & -1.571 \\
\hline LRRK2 & Leucine-rich repeat kinase 2 & 1.677 \\
\hline TCF19 & Transcription factor 19 & -2.217 \\
\hline F7L1 & Transcription factor 7-like 1 (T-cell specific, HMG-box) & -1.762 \\
\hline WNT5A & Wingless-type MMTV integration site family, member 5A & -2.325 \\
\hline WNT7B & Wingless-type MMTV integration site family, member 7B & 2.942 \\
\hline \multicolumn{3}{|c|}{ Target gene } \\
\hline ARL4C & ADP-ribosylation factor-like $4 \mathrm{C}$ & 2.179 \\
\hline AXIN2 & Axin 2 & 1.744 \\
\hline CCND1 & Cyclin D1 & -2.476 \\
\hline CSRNP1 & Cysteine-serine-rich nuclear protein 1 & 1.822 \\
\hline RACGAP1 & Rac GTPase activating protein 1 & -3.201 \\
\hline SPRY2 & Sprouty homolog 2 (Drosophila) & -1.771 \\
\hline SPRY4 & Sprouty homolog 4 (Drosophila) & -2.771 \\
\hline WISP1 & WNT1 inducible signaling pathway protein 1 & 2.489 \\
\hline \multicolumn{3}{|c|}{ Wnt antagonists/inhibitors } \\
\hline APOE & Apolipoprotein E & 1.704 \\
\hline DKK2 & Dickkopf WNT signaling pathway inhibitor 2 & 1.731 \\
\hline EDIL3 & EGF-like repeats and discoidin I-like domains 3 & 2.258 \\
\hline FRZB & Frizzled-related protein & 1.938 \\
\hline $\mathrm{HICl}$ & Hypermethylated in cancer 1 & -1.731 \\
\hline JADE1 & Jade family PHD finger 1 & -1.656 \\
\hline LRP4 & Low density lipoprotein receptor-related protein 4 & 1.979 \\
\hline NARF & Nuclear prelamin A recognition factor & -1.699 \\
\hline NEDD4L & Neural precursor cell expressed, developmentally downregulated 4-like, E3 ubiquitin protein ligase & 1.588 \\
\hline NKD1 & Naked cuticle homolog 1 (Drosophila) & 3.220 \\
\hline NOTUM & Notum pectinacetylesterase homolog (Drosophila) & 2.631 \\
\hline NOV & Nephroblastoma overexpressed & 2.050 \\
\hline PRICKLE1 & Prickle homolog 1 (Drosophila) & 1.536 \\
\hline TLE3 & Transducin-like enhancer of split 3 & 1.714 \\
\hline TRIB2 & Tribbles pseudokinase 2 & -1.637 \\
\hline \multicolumn{3}{|c|}{ Wht activators } \\
\hline DAAM2 & Dishevelled associated activator of morphogenesis 2 & -1.993 \\
\hline PSRC1 & Proline/serine-rich coiled-coil 1 & -2.235 \\
\hline TNIK & TRAF2 and NCK interacting kinase & 1.677 \\
\hline TRAF4 & TNF receptor-associated factor 4 & -1.673 \\
\hline
\end{tabular}

by the upregulation of genes related to synapse formation and neural connectivity. Most interesting, we found that this transition from enteric neural progenitor proliferation to differentiation was accompanied by a considerable inactivation of the canonical Wnt signalling pathway. This, together with previous work, strongly indicates that canonical Wnt activation is one of the driving mechanisms of enteric neural progenitor proliferation and thus might play a role in the homeostasis of this cell pool in vivo and in vitro.

\section{Conflict of Interests}

The authors declare that there is no conflict of interests regarding the publication of this paper. 


\section{Authors' Contribution}

Peter Helmut Neckel and Roland Mohr contributed equally to this work.

\section{Acknowledgments}

The project was supported by a grant from the German Federal Ministry for Education and Research (01GN0967). The authors would like to thank Andrea Wizenmann, Andreas Mack, and Sven Poths for their helpful advice.

\section{References}

[1] J. B. Furness, "The enteric nervous system and neurogastroenterology," Nature Reviews Gastroenterology \& Hepatology, vol. 9, no. 5, pp. 286-294, 2012.

[2] D. Natarajan, M. Grigoriou, C. V. Marcos-Gutierrez, C. Atkins, and V. Pachnis, "Multipotential progenitors of the mammalian enteric nervous system capable of colonising aganglionic bowel in organ culture," Development, vol. 126, no. 1, pp. 157-168, 1999.

[3] G. M. Kruger, J. T. Mosher, S. Bixby, N. Joseph, T. Iwashita, and S. J. Morrison, "Neural crest stem cells persist in the adult gut but undergo changes in self-renewal, neuronal subtype potential, and factor responsiveness," Neuron, vol. 35, no. 4, pp. 657-669, 2002.

[4] M. Metzger, P. M. Bareiss, T. Danker et al., "Expansion and differentiation of neural progenitors derived from the human adult enteric nervous system," Gastroenterology, vol. 137, no. 6, pp. 2063.e4-2073.e4, 2009.

[5] M. Metzger, C. Caldwell, A. J. Barlow, A. J. Burns, and N. Thapar, "Enteric nervous system stem cells derived from human gut mucosa for the treatment of aganglionic gut disorders," Gastroenterology, vol. 136, no. 7, pp. 2214.e3-2225.e3, 2009.

[6] M. J. Saffrey, "Cellular changes in the enteric nervous system during ageing," Developmental Biology, vol. 382, no. 1, pp. 344$355,2013$.

[7] M. D. Gershon, "Developmental determinants of the independence and complexity of the enteric nervous system," Trends in Neurosciences, vol. 33, no. 10, pp. 446-456, 2010.

[8] F. Obermayr, R. Hotta, H. Enomoto, and H. M. Young, "Development and developmental disorders of the enteric nervous system," Nature Reviews Gastroenterology and Hepatology, vol. 10, no. 1, pp. 43-57, 2013.

[9] R. J. Rintala and M. P. Pakarinen, "Long-term outcomes of Hirschsprung's disease," Seminars in Pediatric Surgery, vol. 21, no. 4, pp. 336-343, 2012.

[10] T. A. Heanue and V. Pachnis, "Enteric nervous system development and Hirschsprung's disease: advances in genetic and stem cell studies," Nature Reviews Neuroscience, vol. 8, no. 6, pp. 466479, 2007.

[11] L. Becker, J. Peterson, S. Kulkarni, and P. J. Pasricha, "Ex vivo neurogenesis within enteric ganglia occurs in a PTEN dependent manner," PLoS ONE, vol. 8, no. 3, Article ID e59452, 2013.

[12] T. Uesaka, M. Nagashimada, and H. Enomoto, "GDNF signaling levels control migration and neuronal differentiation of enteric ganglion precursors," The Journal of Neuroscience, vol. 33, no. 41, pp. 16372-16382, 2013.

[13] T. A. Heanue and V. Pachnis, "Expression profiling the developing mammalian enteric nervous system identifies marker and candidate Hirschsprung disease genes," Proceedings of the National Academy of Sciences of the United States of America, vol. 103, no. 18, pp. 6919-6924, 2006.

[14] B. P. S. Vohra, K. Tsuji, M. Nagashimada et al., "Differential gene expression and functional analysis implicate novel mechanisms in enteric nervous system precursor migration and neuritogenesis," Developmental Biology, vol. 298, no. 1, pp. 259-271, 2006.

[15] R. Mohr, P. Neckel, Y. Zhang et al., "Molecular and cell biological effects of 3,5,3'-triiodothyronine on progenitor cells of the enteric nervous system in vitro," Stem Cell Research, vol. 11, no. 3, pp. 1191-1205, 2013.

[16] S. Fleige and M. W. Pfaffl, "RNA integrity and the effect on the real-time qRT-PCR performance," Molecular Aspects of Medicine, vol. 27, no. 2-3, pp. 126-139, 2006.

[17] S. L. Kline, I. M. Cheeseman, T. Hori, T. Fukagawa, and A. Desai, "The human Mis12 complex is required for kinetochore assembly and proper chromosome segregation," The Journal of Cell Biology, vol. 173, no. 1, pp. 9-17, 2006.

[18] E. D. Salmon, D. Cimini, L. A. Cameron, and J. G. DeLuca, "Merotelic kinetochores in mammalian tissue cells," Philosophical Transactions of the Royal Society B: Biological Sciences, vol. 360, no. 1455, pp. 553-568, 2005.

[19] A. A. Ye and T. J. Maresca, "Cell division: kinetochores SKAdaddle," Current Biology, vol. 23, no. 3, pp. R122-R124, 2013.

[20] Y. Lu, Z. Wang, L. Ge, N. Chen, and H. Liu, "The RZZ complex and the spindle assembly checkpoint," Cell Structure and Function, vol. 34, no. 1, pp. 31-45, 2009.

[21] D. G. Johnson and C. L. Walker, "Cyclins and cell cycle checkpoints," Annual Review of Pharmacology and Toxicology, vol. 39, pp. 295-312, 1999.

[22] M. Malumbres, E. Harlow, T. Hunt et al., "Cyclin-dependent kinases: a family portrait," Nature Cell Biology, vol. 11, no. 11, pp. 1275-1276, 2009.

[23] M. V. Gómez-Gaviro, C. E. Scott, A. K. Sesay et al., "Betacellulin promotes cell proliferation in the neural stem cell niche and stimulates neurogenesis," Proceedings of the National Academy of Sciences of the United States of America, vol. 109, no. 4, pp. 1317-1322, 2012.

[24] K. Khodosevich, Y. Watanabe, and H. Monyer, "EphA4 preserves postnatal and adult neural stem cells in an undifferentiated state in vivo," Journal of Cell Science, vol. 124, no. 8, pp. 1268-1279, 2011.

[25] E. Abranches, M. Silva, L. Pradier et al., "Neural differentiation of embryonic stem cells in vitro: a road map to neurogenesis in the embryo," PLoS ONE, vol. 4, no. 7, Article ID e6286, 2009.

[26] V. Balasubramaniyan, N. Timmer, B. Kust, E. Boddeke, and S. Copray, "Transient expression of Oligl initiates the differentiation of neural stem cells into oligodendrocyte progenitor cells," Stem Cells, vol. 22, no. 6, pp. 878-882, 2004.

[27] M. Kolatsi-Joannou, X. Z. Li, T. Suda, H. T. Yuan, and A. S. Woolf, "In early development of the rat mRNA for the major myelin protein $\mathrm{P}_{0}$ is expressed in nonsensory areas of the embryonic inner ear, notochord, enteric nervous system, and olfactory ensheathing cells," Developmental Dynamics, vol. 222, no. 1, pp. 40-51, 2001.

[28] M. I. Morris, D. B.-D. Soglio, A. Ouimet, A. Aspirot, and N. Patey, "A study of calretinin in Hirschsprung pathology, particularly in total colonic aganglionosis," Journal of Pediatric Surgery, vol. 48, no. 5, pp. 1037-1043, 2013.

[29] K. R. Jessen and R. Mirsky, "Glial cells in the enteric nervous system contain glial fibrillary acidic protein," Nature, vol. 286, no. 5774 , pp. $736-737,1980$. 
[30] T. J. Siddiqui, R. Pancaroglu, Y. Kang, A. Rooyakkers, and A. M. Craig, "LRRTMs and neuroligins bind neurexins with a differential code to cooperate in glutamate synapse development," The Journal of Neuroscience, vol. 30, no. 22, pp. 7495-7506, 2010.

[31] S. Chen, O. Gil, Y. Q. Ren, G. Zanazzi, J. L. Salzer, and D. E. Hillman, "Neurotrimin expression during cerebellar development suggests roles in axon fasciculation and synaptogenesis," Journal of Neurocytology, vol. 30, no. 11, pp. 927-937, 2002.

[32] R. Janz and T. C. Südhof, "SV2C is a synaptic vesicle protein with an unusually restricted localization: anatomy of a synaptic vesicle protein family," Neuroscience, vol. 94, no. 4, pp. 12791290, 1999.

[33] B. Marquèze, F. Berton, and M. Seagar, "Synaptotagmins in membrane traffic: which vesicles do the tagmins tag?" Biochimie, vol. 82, no. 5, pp. 409-420, 2000.

[34] B. C. Jongbloets and R. J. Pasterkamp, "Semaphorin signalling during development," Development, vol. 141, no. 17, pp. 32923297, 2014.

[35] M. Metzger, S. Conrad, T. Skutella, and L. Just, "RGMa inhibits neurite outgrowth of neuronal progenitors from murine enteric nervous system via the neogenin receptor in vitro," Journal of Neurochemistry, vol. 103, no. 6, pp. 2665-2678, 2007.

[36] J. M. Spin, S. Nallamshetty, R. Tabibiazar et al., "Transcriptional profiling of in vitro smooth muscle cell differentiation identifies specific patterns of gene and pathway activation," Physiological Genomics, vol. 19, pp. 292-302, 2005.

[37] J. M. Baisden, Y. Qian, H. M. Zot, and D. C. Flynn, “The actin filament-associated protein AFAP-110 is an adaptor protein that modulates changes in actin filament integrity," Oncogene, vol. 20, no. 44, pp. 6435-6447, 2001.

[38] L. E. Peri, K. M. Sanders, and V. N. Mutafova-Yambolieva, "Differential expression of genes related to purinergic signaling in smooth muscle cells, PDGFR $\alpha$-positive cells, and interstitial cells of Cajal in the murine colon," Neurogastroenterology \& Motility, vol. 25, no. 9, pp. e609-e620, 2013.

[39] S. J. Winder, B. G. Allen, O. Clément-Chomienne, and M. P. Walsh, "Regulation of smooth muscle actin-myosin interaction and force by calponin," Acta Physiologica Scandinavica, vol. 164, no. 4, pp. 415-426, 1998.

[40] M. L. Mancini, J. M. Verdi, B. A. Conley et al., "Endoglin is required for myogenic differentiation potential of neural crest stem cells," Developmental Biology, vol. 308, no. 2, pp. 520-533, 2007.

[41] F. T. L. van der Loop, G. Schaart, E. D. J. Timmer, F. C. S. Ramaekers, and G. J. J. M. van Eys, "Smoothelin, a novel cytoskeletal protein specific for smooth muscle cells," The Journal of Cell Biology, vol. 134, no. 2, pp. 401-411, 1996.

[42] M. A. D’Angelo, J. S. Gomez-Cavazos, A. Mei, D. H. Lackner, and M. W. Hetzer, "A change in nuclear pore complex composition regulates cell differentiation," Developmental Cell, vol. 22, no. 2, pp. 446-458, 2012.

[43] J. J.-C. Lin, Y. Li, R. D. Eppinga, Q. Wang, and J.-P. Jin, “Chapter 1: roles of caldesmon in cell motility and actin cytoskeleton remodeling," International Review of Cell and Molecular Biology, vol. 274, pp. 1-68, 2009.

[44] S. B. Marston and C. W. J. Smith, "The thin filaments of smooth muscles," Journal of Muscle Research and Cell Motility, vol. 6, no. 6, pp. 669-708, 1985.

[45] K. M. Sanders and S. M. Ward, "Kit mutants and gastrointestinal physiology," The Journal of Physiology, vol. 578, no. 1, pp. 33-42, 2007.
[46] L. S. Campos, "Neurospheres: insights into neural stem cell biology," Journal of Neuroscience Research, vol. 78, no. 6, pp. 761769, 2004.

[47] A. Ring, Y.-M. Kim, and M. Kahn, "Wnt/catenin signaling in adult stem cell physiology and disease," Stem Cell Reviews and Reports, vol. 10, no. 4, pp. 512-525, 2014.

[48] D. C. Berwick and K. Harvey, "LRRK2: an éminence grise of Wnt-mediated neurogenesis?" Frontiers in Cellular Neuroscience, vol. 7, article 82, 2013.

[49] S. Kakugawa, P. F. Langton, M. Zebisch et al., "Notum deacylates Wnt proteins to suppress signalling activity," Nature, vol. 519, no. 7542, pp. 187-192, 2015.

[50] Y. Mii and M. Taira, "Secreted Wnt 'inhibitors' are not just inhibitors: regulation of extracellular Wnt by secreted Frizzledrelated proteins," Development Growth \& Differentiation, vol. 53, no. 8, pp. 911-923, 2011.

[51] Y. Kawano and R. Kypta, "Secreted antagonists of the Wnt signalling pathway," Journal of Cell Science, vol. 116, part 13, pp. 2627-2634, 2003.

[52] A. Ohazama, E. B. Johnson, M. S. Ota et al., "Lrp4 modulates extracellular integration of cell signaling pathways in development," PLoS ONE, vol. 3, no. 12, Article ID e4092, 2008.

[53] Y. Ding, Y. Zhang, C. Xu, Q.-H. Tao, and Y.-G. Chen, "HECT domain-containing $\mathrm{E}_{3}$ ubiquitin ligase $\mathrm{NEDD}_{4} \mathrm{~L}$ negatively regulates Wnt signaling by targeting dishevelled for proteasomal degradation," The Journal of Biological Chemistry, vol. 288, no. 12, pp. 8289-8298, 2013.

[54] A. Ishikawa, S. Kitajima, Y. Takahashi et al., "Mouse Nkd1, a Wnt antagonist, exhibits oscillatory gene expression in the PSM under the control of Notch signaling," Mechanisms of Development, vol. 121, no. 12, pp. 1443-1453, 2004.

[55] D. W. Chan, C.-Y. Chan, J. W. P. Yam, Y.-P. Ching, and I. O. L. Ng, "Prickle-1 negatively regulates $\mathrm{Wnt} / \beta$-catenin pathway by promoting Dishevelled ubiquitination/degradation in liver cancer," Gastroenterology, vol. 131, no. 4, pp. 1218-1227, 2006.

[56] K. Sakamoto, S. Yamaguchi, R. Ando et al., "The nephroblastoma overexpressed gene $(\mathrm{NOV} / \mathrm{ccn} 3)$ protein associates with Notch1 extracellular domain and inhibits myoblast differentiation via Notch signaling pathway," The Journal of Biological Chemistry, vol. 277, no. 33, pp. 29399-29405, 2002.

[57] A. Caruso, M. Motolese, L. Iacovelli et al., "Inhibition of the canonical Wnt signaling pathway by apolipoprotein $\mathrm{E}_{4}$ in $\mathrm{PC} 12$ cells," Journal of Neurochemistry, vol. 98, no. 2, pp. 364-371, 2006.

[58] A. J. Hanson, H. A. Wallace, T. J. Freeman, R. D. Beauchamp, L. A. Lee, and E. Lee, "XIAP monoubiquitylates Groucho/TLE to promote canonical Wnt signaling," Molecular Cell, vol. 45, no. 5, pp. 619-628, 2012.

[59] A. Takai, H. Inomata, A. Arakawa, R. Yakura, M. MatsuoTakasaki, and Y. Sasai, "Anterior neural development requires Dell, a matrix-associated protein that attenuates canonical Wnt signaling via the Ror2 pathway," Development, vol. 137, no. 19, pp. 3293-3302, 2010.

[60] Y. Katoh and M. Katoh, "FGF signaling inhibitor, SPRY4, is evolutionarily conserved target of WNT signaling pathway in progenitor cells," International Journal of Molecular Medicine, vol. 17, no. 3, pp. 529-532, 2006.

[61] P. Ordóñez-Morán, A. Irmisch, A. Barbáchano et al., "SPROUTY2 is a $\beta$-catenin and FOXO3a target gene indicative of poor prognosis in colon cancer," Oncogene, vol. 33, no. 15, pp. 1975-1985, 2014. 
[62] T. Taketomi, D. Yoshiga, K. Taniguchi et al., "Loss of mammalian Sprouty2 leads to enteric neuronal hyperplasia and esophageal achalasia," Nature Neuroscience, vol. 8, no. 7, pp. 855857, 2005.

[63] R. Di Liddo, T. Bertalot, A. Schuster et al., "Anti-inflammatory activity of Wht signaling in enteric nervous system: in vitro preliminary evidences in rat primary cultures," Journal of Neuroinflammation, vol. 12, no. 1, p. 23, 2015. 

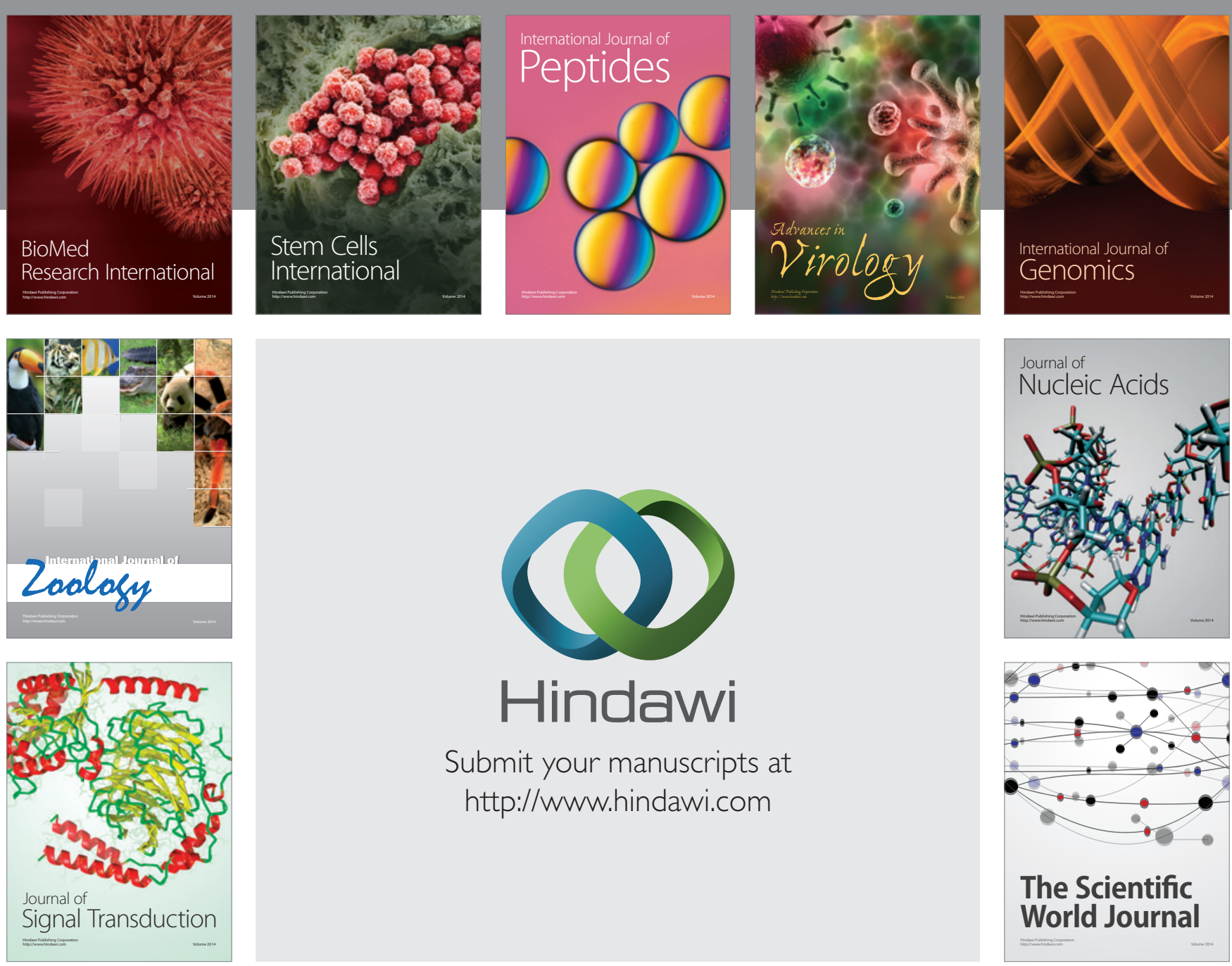

Submit your manuscripts at

http://www.hindawi.com
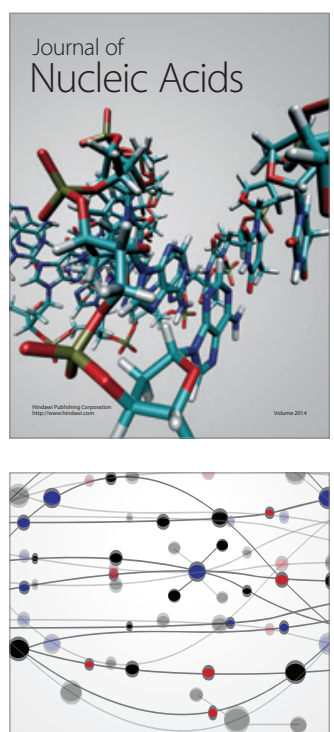

The Scientific World Journal
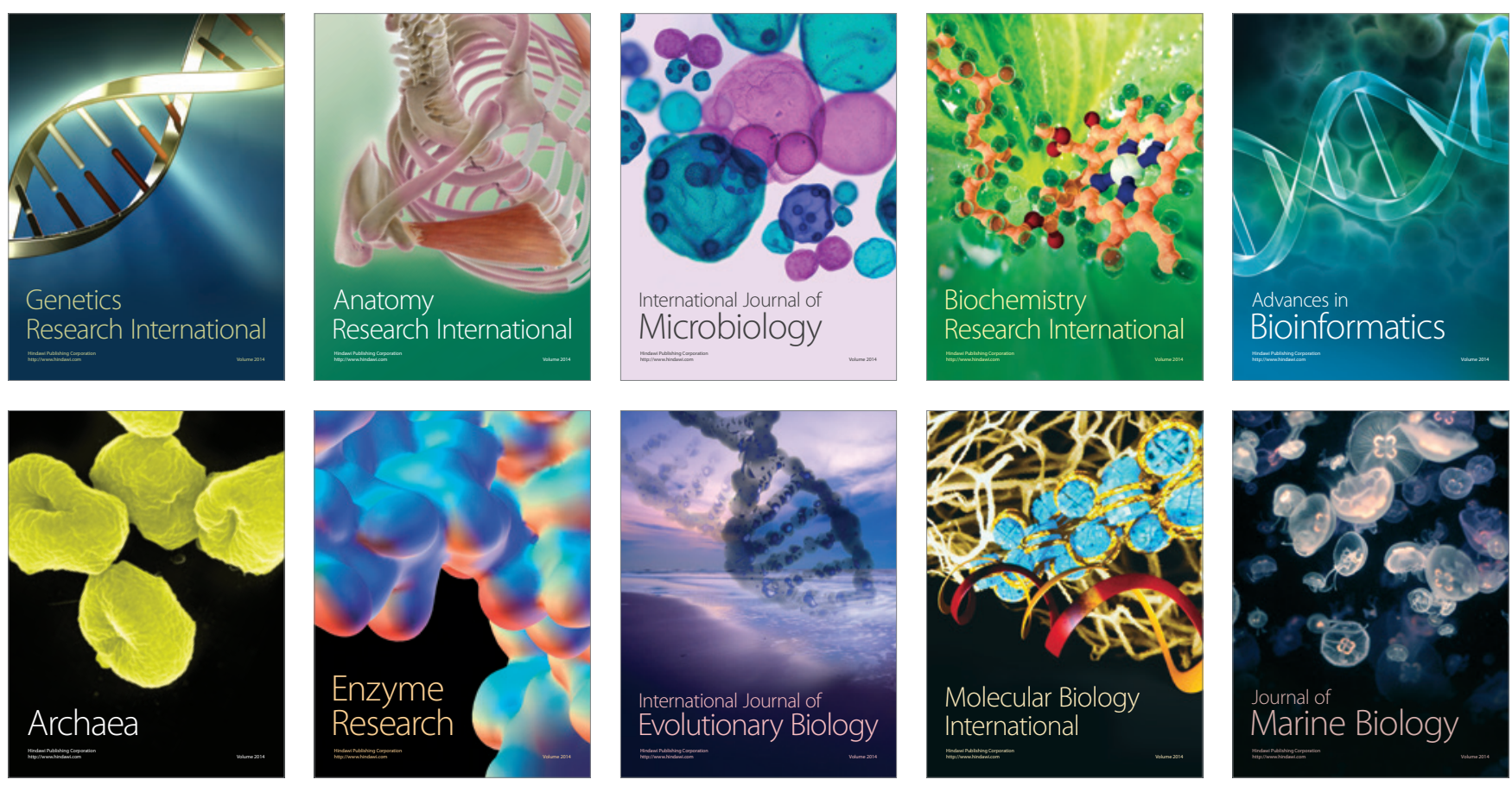